\title{
OPTIMIZATION DESIGN OF BOX STRUCTURE FOR PREFABRICATED SUBSTATION
}

\author{
Feng Zhengmao $^{1}$, Sui Xiuhua ${ }^{2}$, Chen Hongzhi ${ }^{3}$, Liu Xiaoyu ${ }^{4}$, Zhao Changzheng ${ }^{5}$, \\ Wang Fengjiao ${ }^{6}$, Zhao Yinghai ${ }^{7}$
}

${ }^{1}$ Shandong Taikai Apparatus Complete co.ltd, Taikai Group, Taian, 271000, China

${ }^{2}$ College of Mechanical and Electronic Engineering, Shandong University of Science and Technology, Qingdao, 266590, China

${ }^{3}$ College of Mechanical and Electronic Engineering, Shandong University of Science and Technology, Qingdao, 266590, China

${ }^{4}$ College of Mechanical and Electronic Engineering, Shandong University of Science and Technology, Qingdao, 266590, China

${ }^{5}$ College of Mechanical and Electronic Engineering, Shandong University of Science and Technology, Qingdao, 266590, China

${ }^{6}$ College of Mechanical and Electronic Engineering, Shandong University of Science and Technology, Qingdao, 266590, China

${ }^{7}$ Taian City Central Hospital, Taian, 271000, China

\begin{abstract}
Based on the topography and climate characteristics of Northwest China, box structure for prefabricated substation used in the region is designed, the finite element method is developed to calculate of its strength, and the rationality of the structural design is verified. Used the finite element analysis software, optimizing the supporting column section of the box structure is also studied. The results show that the quality of the corner column is reduced by $12.9 \%$ and the quality of the side column is reduced by $13.51 \%$ under the condition of meeting the requirements of wind and snow resistance performance.
\end{abstract}

Keywords: - box, design, finite element, optimization

\section{INTRODUCTION}

Prefabricated substation, as an important line connection point in the power grid, plays an important role in power grid security and power supply reliability[1-2]. Because it is installed outdoors for a long time, prefabricated substation is susceptible to the erosion of heavy storms, high wind, and undetermined natural forces[3-6]. It is of great significance to design a box structure for prefabricated substation with stable performance.

Although the shape of box structure for the substation cabinet is different[7-8], its structure is generally composed of base, body case, top cover and some auxiliary parts. The parts are joined together by welding or fasteners such as bolts[9-10]. This paper designs the prefabricated substation box structure which is used in special geographical situations, according to the geographical location and climatic conditions of the area, optimization and performance analysis of the substation box is also studied.

\section{BOX STRUCTURE DESIGN}

\subsection{Design Requirements}

The designed box structure for prefabricated substation is used in the northwestern part of China. The area is prone to extreme weather such as snowstorms and gale, and the local winter temperature is so low that many of the snowfall can easily cause snowdrift. So in this paper the designed box structure for prefabricated substation should have the ability to withstand $12-$ level wind speed and $60-70 \mathrm{~cm}$ snow load. According to this requirement, the maximum wind pressure can be determined by the formula 2.1 to be $0.7225 \mathrm{kN} / \mathrm{m}^{2}$.

$$
w_{0}=\frac{v_{0}^{2}}{1600}
$$

Where: $w_{0}$ is the wind pressure and is the wind speed.

According snow pressure calculation formula 2.2,

$$
s_{k}=\mu_{r} \rho g h
$$

Where: $\mathrm{S}_{\mathrm{K}}$ is snow load; 
$\rho$ is the density of snow, and the average density of snow in northwestern China is about $150 \mathrm{~kg} / \mathrm{m}^{3}$;

$g$ is the acceleration of gravity;

$h$ is the maximum snow thickness of the year;

$\mu_{r}$ is the snow distribution coefficient of the house area.

Using this equation we can get the maximum snow load is about $1 \mathrm{kN} / \mathrm{m}^{2}$.

\subsection{Box Structure Design Calculation}

\subsubsection{Box Structure}

Considering the substation's floor space, economic cost, ease of manufacture, reliability of power supply and other factors, in this paper the "order" type structure layout is developed to design the prefabricated substation. This is mainly because the spacing of the internal equipment for the prefabricated substation is large, the main circuit is convenient to wire, and it also features simple structure , good heat dispersion and ventilation [3].

The outer dimensions of the prefabricated substation box are mainly determined by the basic dimensions of the three chambers, high pressure chamber, low pressure chamber and transformer chamber. The dimensions of each chamber are mainly depended on internal electrical components, maintenance distance and insulation distance. The box of the prefabricated substation is composed of top cover, body case and base. So the top cover is $7700 \mathrm{~mm}$ long, 3200mm wide and $300 \mathrm{~mm}$ high, the dimension of base and body case are $7500 \mathrm{~mm}$ and $3000 \mathrm{~mm}$, the column height is $2740 \mathrm{~mm}$, and the base is standing $160 \mathrm{~mm}$ tall. In addition, three access doors are designed, which are shown in Figure 1.

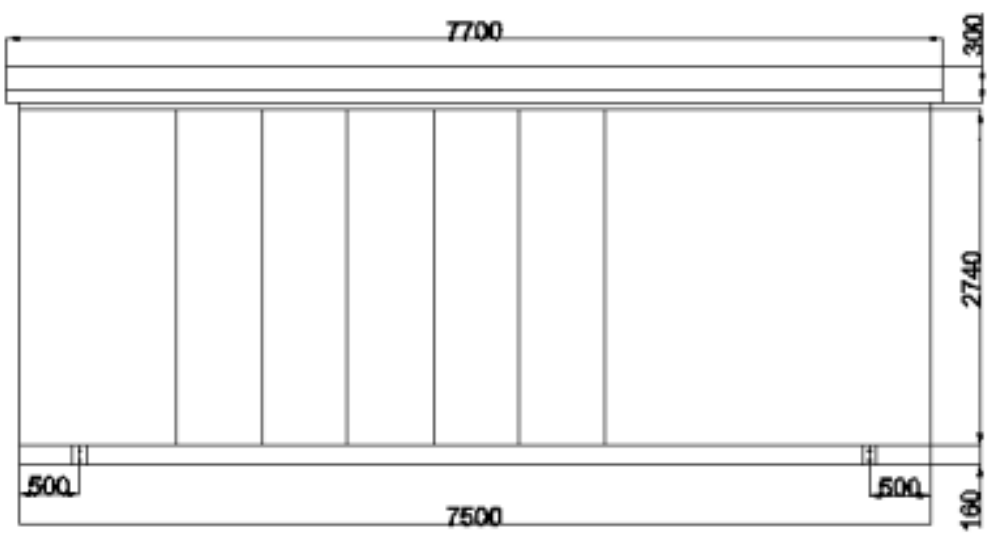

Fig 1: Primary and left view of prefabricated substation box

\subsubsection{Base Structure}

The base of box structure is used to bear the weight of all the equipment inside. Because the overall size of the designed base is $7500 \mathrm{~mm}$ long, $3000 \mathrm{~mm}$ wide, $160 \mathrm{~mm}$ high, the Q235A double channel steel butt welding should be used when welding the base. The place where heavier devices are installed is reinforced with angle steel, and a layer of slab is laid on the upper surface of the base, as shown in Figure 2.

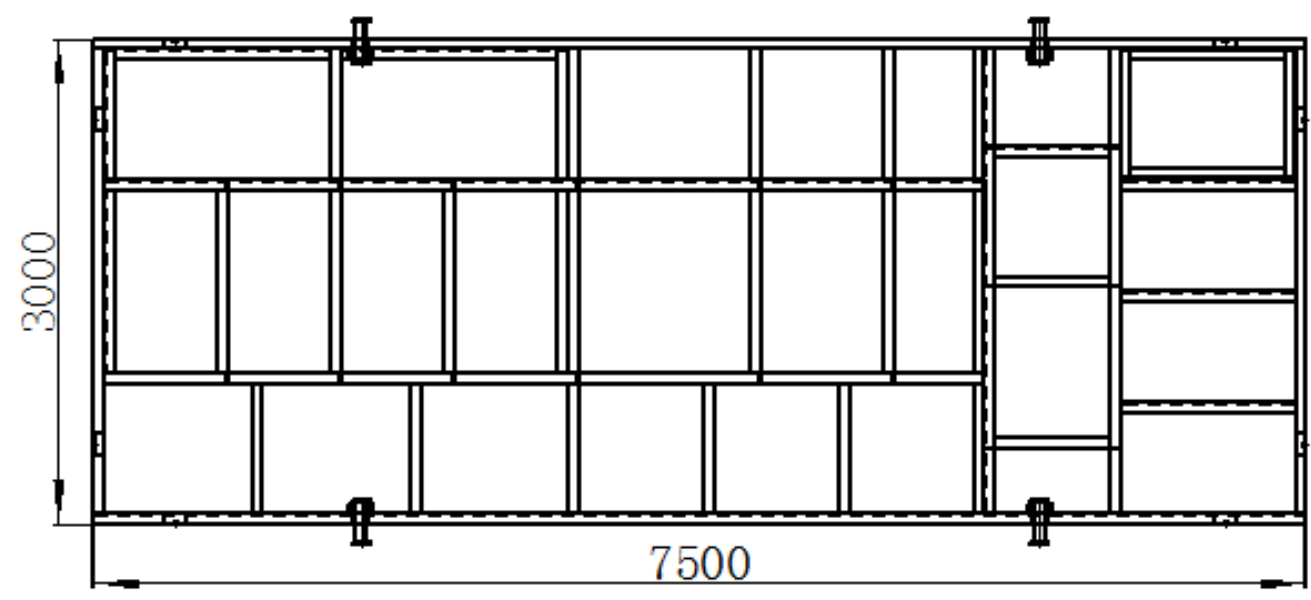

Fig 2: Base structure diagram of prefabricated substation 


\subsubsection{Top Cover Design}

The top cover is the upper part of the prefabricated substation and the load-bearing part. Because the doublesloping roof has the advantages of being simple and strong, good water drainage, and corrosion resistance, the top cover is designed as a double slope with the slope of $6.4^{\circ}$, as shown in Figure 3, which is not only conducive to the slippage of rainwater, but also reduces the influence of uneven snow on the roof.

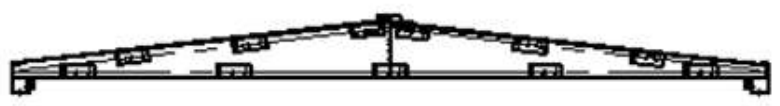

Fig 3: Top cover

In order to avoid the damage caused by rain dropping on the box, extending the length and width of the top cover respectively make them larger than the box base, the triangular span beams are directly lapped on the outer eaves of the top cover. Purlins are arranged along each side of the span beam to connect the adjacent two span beams, and roof slabs are laid between the span beams to support the vertical load on the top.

\subsubsection{Integral 3D Model of Box}

The prefabricated substation is designed three maintenance doors, the columns are arranged on the grounds of the position of these doors and other factors. Then the box structure is assembled by Solid Works 3D modeling software, which is shown in Figure 4.

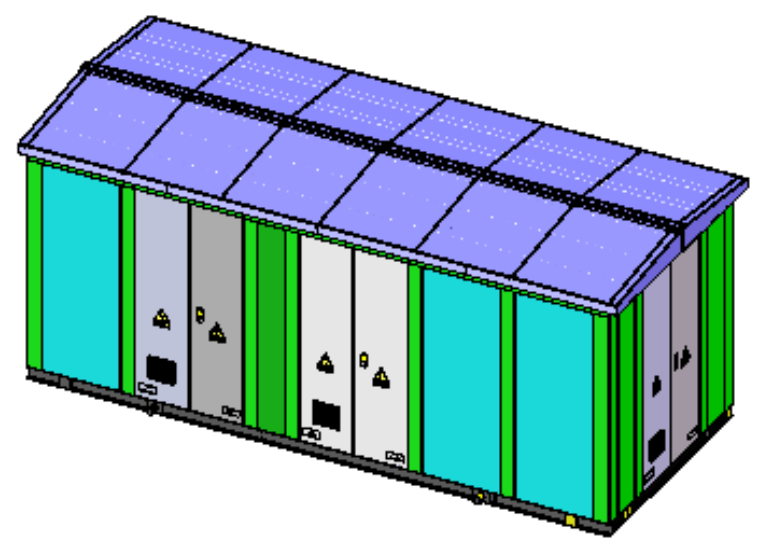

Fig 4: Assembly model

\subsection{Analysis of Wind and Snow Resistance of Box}

According to the geographic environment and climatic characteristics, the performance of designed box structure is studied under the circumstance of wind and snow load acting together, which is loaded with 12 wind speed wind load and 60-70 cm snow load. The deformation trend and stress state are obtained as shown in Figure 5.

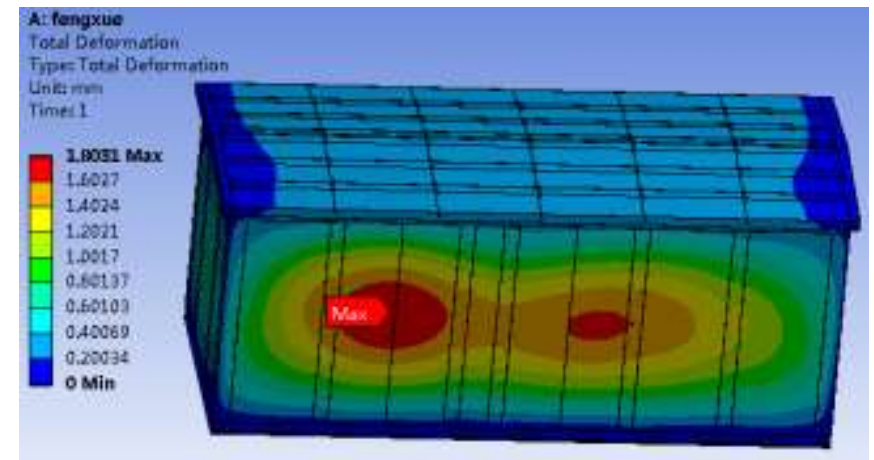

(a) Deformable cloud chart

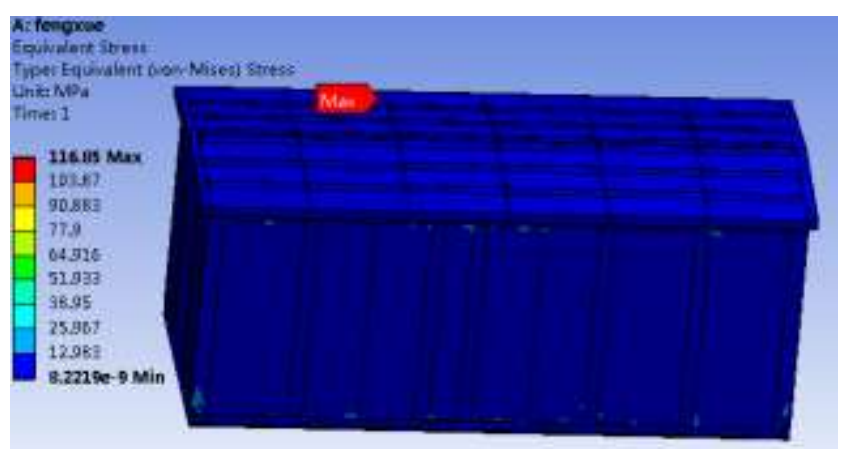

(b) Stress cloud map

Fig 5: Wind and snow resistance performance results 
As can be seen from above figure that under the combined action of wind and snow loads, the maximum deformation of prefabricated substation box is at the wall panel position of the wind receiving surface, which is $1.8031 \mathrm{~mm}$. The maximum equivalent stress of the box occurs at the same position when the snow load works solely, which is 116.85 $\mathrm{MPa}$ and less than the allowable stress of the material. So the designed box structure for prefabricated substation meets the strength requirements.
Base on the box structural characteristics, optimizing the corner column and side column of the box is studied. The side length $\mathrm{P} 1$ of the corner column and the side length P2 of the side column are respectively set as optimization variables, where the side length parameter of the corner column is set to DS_L1 and the side length of the side column is set to DS_L2. Meanwhile the range of the variable $\mathrm{P} 1$ is $175 \mathrm{~mm}-215 \mathrm{~mm}$, and $\mathrm{P} 2$ is $140-190 \mathrm{~mm}$, as shown in Figure 6.

\section{OPTIMIZE THE DESIGN}

\begin{tabular}{|c|c|c|c|c|}
\hline \multicolumn{5}{|c|}{ Table of Schematic C2: Optimization } \\
\hline & A & B & C & D \\
\hline 1 & \multicolumn{4}{|l|}{ - Input Parameters } \\
\hline 2 & Name & Lower Bound & Upper Bound & \\
\hline 3 & P1 - P5@DS_L1@sketch@jiaolizhu.Part & 175 & 215 & \\
\hline 4 & P2 - P7@DS_L2@sketch2@bianlizhu.Part & 140 & 190 & \\
\hline 5 & \multicolumn{4}{|l|}{ I Parameter Relationships } \\
\hline 6 & Name & Left Expression & Operator & Right Expression \\
\hline * & New Parameter Relationship & New Expression & $<=$ & New Expression \\
\hline
\end{tabular}

Fig 6: The range of design variables

The allowable strength of the prefabricated substation box structure is taken as the constraint condition, which is set to $\mathrm{P} 5 \leq 130 \mathrm{MPa}$ so as to leave a certain safety margin. The minimum mass of the corner column and the side column are used as the objective function. The mathematical model for the optimization design is shown in Figure 7. Three groups of optimal solutions are obtained by using direct optimization method, as shown in Figure 8.

\begin{tabular}{|c|c|c|c|c|c|c|c|}
\hline & A & B & C & D & $\mathrm{E}$ & $\mathrm{F}$ & G \\
\hline 1 & \multirow{2}{*}{ Name } & \multirow{2}{*}{ Parameter } & \multicolumn{2}{|l|}{ Objective } & \multicolumn{3}{|c|}{ Constraint } \\
\hline 2 & & & Type & Target & Type & Lower Bound & Upper Bound \\
\hline 3 & Minimize P3 & P3 - jiaolizhu-1 Mass & Minimize & & No Constraint & & \\
\hline 4 & Minimize P4 & P4 - bianlizhu-1 Mass & Minimize $\quad \mp$ & & No Constraint $\quad$ I & & \\
\hline 5 & $\mathrm{P} 5<=130 \mathrm{MPa}$ & P5 - Equivalent Stress Maximum & No Objective $I$ & & Values $<=$ Upper Bound $\quad$ & & 130 \\
\hline * & & Select a Parameter & & & & & \\
\hline
\end{tabular}

Fig 7: Prefabricated substation optimization design mathematical model

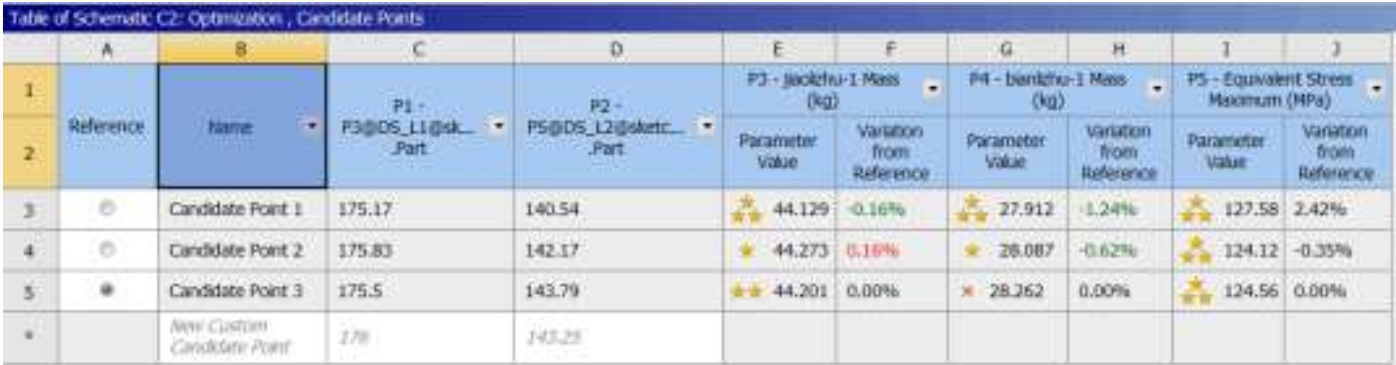

Fig 8: Optimal design optimization

It can be seen from Figure 8 that the optimal solution is obtained, the side length of the corner column is $175.17 \mathrm{~mm}$ and the side length of the side column is $140.54 \mathrm{~mm}$, at this time the maximum stress is $127.58 \mathrm{MPa}$, which is less than the allowable stress. Then the lightest quality is achieved. The side length of the corner column and the side column are make to round off, after that, the side length of the corner column is $175 \mathrm{~mm}$, and the side column is $140 \mathrm{~mm}$.

\section{PERFORMANCE COMPARISON OF BOX OPTIMIZATION}

The model of optimized box structure is make by solidworks software, then the finite element method is used to analyze the wind and snow resistance. The stress and deformation cloud maps are shown in Figures 9 and Figures 10. 


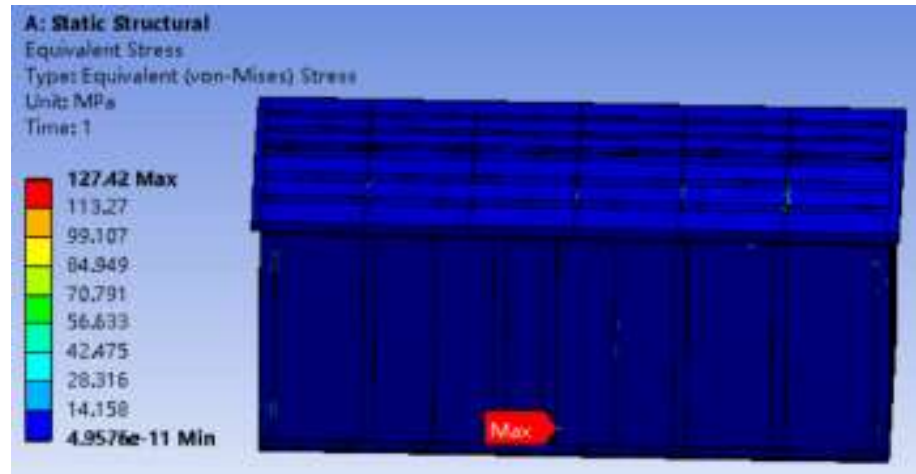

Fig 9: Equivalent stress cloud diagram after optimization

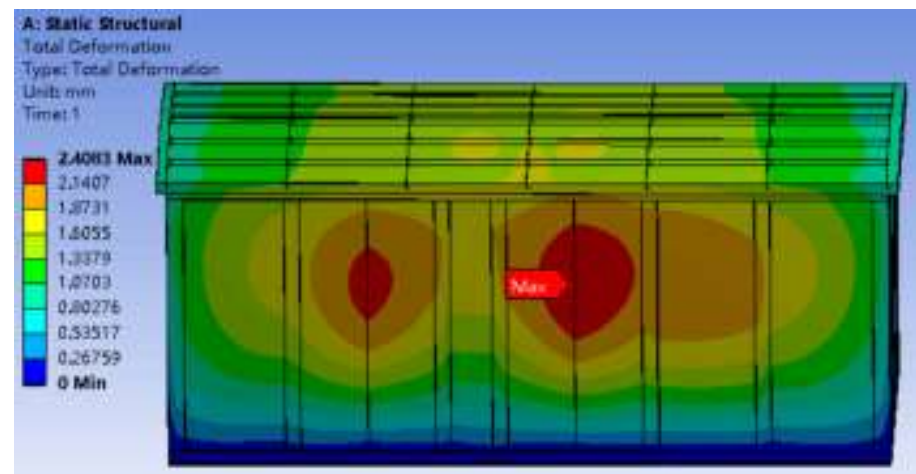

Fig 10: Total deformation cloud diagram after optimization

As seen in Figure 9 and Figure 10 , the maximum stress of the optimized box structure is $127.42 \mathrm{MPa}$, appearing at the junction of the column and the wall panel, which meets the requirements of the allowable stress. The optimized deformation of the prefabricated substation box is $2.4083 \mathrm{~mm}$, which appears on the windward wall panel and also meets the design requirements.

\section{CONCLUSION}

The box structure for the prefabricated substation which is applied to the northwestern China is designed in this paper, meanwhile the wind and snow resistance is also analyzed, and optimizing its structure. The research results show that the maximum stress of the prefabricated substation box structure is less than the allowable stress of the material under the combined action of wind and snow load, which can meet the design requirements of prefabricated substation safety and stability.

\section{REFERENCES}

[1] Huang D P, Application of $35 \mathrm{kV}$ box-type transformer substation in rural power grid reformation, Relay, 2004.

[2] Song D S, Yan L W, Improvement of Box-Type Substation for Port, Applied Mechanics \& Materials, 2013.
[3] Guo Lei, Selection of box substation design in engineering design, Computer and telecom, 2016(5).

[4] Wei Min, Design and Research of $10 \mathrm{kV}$ Smart prefabricated Substation, Huaqiao University,2013.

[5] A.G.Davenport, How can we simplify and generalize wind loads, Journal of Wind Engineering and Industrial Aerodynamics, 1995,54.

[6] Chen Yong, Dai Bin, Zhou Yunbin, Analysis method of box forces in $110 \mathrm{kV}$ preloaded substation based on finite element principle ,2014 Yunnan electric power technology BBS,2014.

[7] Guo Lei, Selection of box substation design in engineering design, Computer and telecom, 2016(5).

[8] Wei Min, Design and Research of $10 \mathrm{kV}$ Smart prefabricated Substation, Huaqiao University,2013.

[9] Wang Qingbao, Pre-assembled prefabricated Substation housing design, Science and technology,2017(2).

[10] Li Ying, Research on Loss and Thermal Problems of Box Substation, Shenyang University of Technology,2017.

[11] Pu Guangyi, ANSYS Workbench basic tutorial and examples explain, China Water Conservancy and Hydropower Press,2013.

[12] Zhang Yan, et al. ANSYS Workbench 15.0 finite element analysis from entry to mastery, Mechanical Industry Press, 2014. 


\section{BIOGRAPHIES}

Feng Zhengmao, research major: mechanical and electronic engineering, email:fengzhm@126.com

Sui Xiuhua, corresponding author, associate professor, research major: mechanical and electronic engineering, email: suixh@126.com

Chen Hongzhi, master degree student, email: chenhz15650183781@163.com

Liu Xiaoyu, master degree student, email: L1596638274@163.com

Zhao Changzheng, master degree student, email: 17806263313@163.com

Wang Fengjiao, master degree student, email: 761546026 @qq.com

Zhao Yinghai, research major: mechanical and electronic engineering, email: zyh8586@163.com 